\title{
Importance of feedback, training and media format for students' reflective practice
}

\author{
Barbara T. Miller \\ FHNW University of Applied Sciences and Arts Northwestern Switzerland \\ Barbara.miller@fhnw.ch \\ Larssyn Staley \\ FHNW University of Applied Sciences and Arts Northwestern Switzerland \\ Larssyn.staley@fhnw.ch
}

Purpose: The purpose of this student-centred study is two-fold: to better understand
how students perceive the role of reflection in their learning, both for their degrees
and for their development as future leaders and how lecturers can best use feedback,
training and various media to support and encourage student development.

Study design/methodology/approach: A class of undergraduate students were surveyed at the beginning and end of a semester on their preferred learning styles. Follow-up interviews were also held with selected participants. During the semester, students were exposed to various formats of reflection: individual written reflections, video reflections and peer reflections. Students received both training in reflection and feedback on their reflections. In the survey and interviews, students were asked about the perceived benefits of such learning formats for their current studies and future careers.

Findings: Students indicated an increased ability to reflect honestly and confront their weaknesses. Students also indicated a stronger preference for either the individual written reflection or the video reflection over the peer reflection. Students saw benefit in the greater time that an individual written reflection provided as well as the multimodal aspects of the video reflection, which helped them to reflect in a new way. Additionally, the feedback students received played a big role in allowing the students to feel more comfortable and reflect more honestly.

Originality/value: Previous studies have focused on a variety of factors that affect students' perception of reflection. This study takes a closer look at the effect of feedback and media format on students' perceived benefits.

Keywords: reflection, learning, feedback

\section{Introduction}

A common aim among many tertiary education programs is to provide young adults with the education they need to become active members of society and meet industry demands so that today's students can become tomorrow's leaders. Students in such programs are often eager to receive a quick-fix list of characteristics needed to be an effective leader. However, as so clearly stated by Kets de Vries \& Korotov (2012, p. 266), success in leadership takes time and rests on one's ability to reflect, a key component of methods of transformative life-long learning. Reflection, and in turn transformational leadership, requires encouragement, training and feedback (Kets de Vries \& Korotov, 2012, p. 266).

This paper explores undergraduates' perceptions of reflections at the beginning and end of a semester in which they were asked to engage in various types of reflections on which they received both encouragement and feedback. Next, the role of the format of reflection, for example, individual written reflections, vlogs and peer reflections, and the impact of the lecturer's feedback on the students' perception of the benefits they received from such exercises are assessed.

In the following section, a brief overview of previous research on the factors in the learning environment that affect students' reflections is provided. This overview lays the framework for 
the factors included in the present study. Section three outlines our mixed-method approach and describes the participants in this study. This is followed by the key findings gathered from a before and after survey and interviews with individual students. The paper concludes with key insights and suggestions for further research on the potential correlation between reflection format and depth.

\section{Previous Research}

Experiential learning theory, first described by Kolb (1984), describes learning as a process whereby knowledge is created through the transformation of students' experience and emphasizes reflection as an integral part of all learning activities. Self-reflection leads to better decisions, ultimately enabling leaders to focus on what is important and what might be done differently (Schön, 1983). The role of reflection has been shown to be key in experiential, transformative and self-regulated learning. In an experimental study on the effectiveness of experiential learning strategies, in which learning relies on both experience and reflection as key components of the learning process, Leal-rodríguez \& Albort-morant (2019) found that reflection strategies fostered "students' understanding of theoretical concepts and lead[s] to the attainment of superior performance” (Leal-rodríguez \& Albort-morant, 2019, p. 102). Additionally, by reflecting on two previous studies of how lecturers used self-reflection to reflect on their teaching, Kreber (2004) was able to review two different models of reflection based on different theories of learning, Mezirow's (1991) theory of transformative learning and Zimmerman \& Schunk's (1989) self-regulated learning. Kreber (2004) used two previous studies as a starting point to discuss differences in the theory behind them and posited that "depending on the kind of reflection individuals engage in, the nature of learning will vary" (Kreber, 2004, p. 32). Through the analysis and comparison of these studies, Kreber found that although most informants reported that they engage in self-reflection, their conception of what that is differs greatly. With this in mind, both lecturers and researchers must be precise in their definition and expectations of what a reflection is so that relevant comparisons and conclusions can be made.

According to Kreber (2004), the term critical reflection has been used to mean anything from constructive self-criticism to including a reflection on ethics, morals, equity and respect. This paper relies on Boud's (2001, p. 10) definition of reflection.

Reflection has been described as a process of turning experience into learning, that is, a way of exploring experience in order to learn new things from it. [...] Reflection involves taking the unprocessed, raw material of experience and engaging with it as a way to make sense of what has occurred. It involves exploring often messy and confused events and focusing on the thoughts and emotions that accompany them.

This definition contains two key elements relevant to this study: first, that reflection provides the connection between experience and learning and second that one has to actively engage in a process of sense making of thoughts, emotions and experiences.

In addition to needing a clear understanding of what is meant by reflection, the context in which the reflection takes place and the actions or events being reflected on, have been shown to influence the resulting reflection. According to Bruno \& Dell'Aversana (2018), several factors affect the depth of students' self-reflections, such as frequency of reflections, presence or absence of a grade (cf. Boud, 2001; Dyment \& Connell, 2011), the detail of the instructions (Dyment \& Connell, 2011), and lack of resources, recognition and appreciation (Threlfall, 2014).

With these factors in mind, Bruno \& Dell'Aversana (2018) focused on trying to create an environment that encouraged "non-mechanical, non-linear, non-intuitive” reflections (p. 347). 
They found that the depth of the reflective practice is dependent on the learning environment. In their 2018 study, students were required to complete reflective journals each week. Although, these journals were not part of the course assessment, students received feedback on them. The feedback focused specifically on the level of reflection shown through the use of mental language: 0-non-reflective, 1-declarative reflective, 2-relational reflective, 3-interpretative reflective, and 4-critical reflective.

Bruno and Dell'Aversana (2018) found that after weeks when students were required to take on a trainer role, the depth of their reflections significantly improved. Incremental improvement was also shown over the course of the study. However, they underscored that "reflective practice development is not linear but is connected to learning environment conditions which can enhance or inhibit reflection" (p. 354). These conditions include the role of the students in the learning process (i.e. trainer role), the type of task (i.e. involvement on the cognitive, relational and affective level) and the type and detail of the specific journal entry instructions.

Cheng \& Chau (2009) investigated different outcomes according to the media format of the reflection, i.e. written and video reflections, and showed the role that the form and medium have on the resulting reflections. They posited that video reflections could potentially lead to deeper learning based on two assumptions. First, reflections may be improved through the construction of connections "between verbal and visual representations of the same information". This alignment can reduce the cognitive load thus enabling more room for the information to be stored in one's memory (Cheng \& Chau, 2009; cf. Moreno \& Mayer, 2000; Sweller, Merrienboer, \& Paas, 1998). Second, they posit that the quality of reflection is linked to motivation (Orland-barak, 2007, p. 37) and that students will be encouraged by the peer feedback they will potentially receive and motivated by the opportunity to take more control regarding the format and output of the assignment (Tosh, Light, Fleming, \& Haywood, 2005).

The quality of the reflections in Cheng \& Chau (2009) were also measured using levels of reflection [10]. But in contrast to Bruno \& Dell'Aversana's (2018) 5 levels (0-4) [7], here only three levels were used: recall (in which one describes experiences "without looking for alternative explanations"), rationalization (in which one looks for relationships between experiences, interprets them and makes generalizations) and reflectivity (in which one indicated an "intention to change/improve").

Although 11 of the 15 students reported a greater motivation to "showcase" their work if more of their peers would view it, 13 of the 15 students reported that video reflections required both more time and effort than written reflections and eight of the 15 students reported that expressing themselves in video reflections is more difficult than a text equivalent. Thus, videobased reflections potentially raise the workload and the motivation.

When assessing the level of reflection, Cheng \& Chau (2009) found that the medium (text- or video-based) had no effect of the level of reflection. The majority of these students' reflections remained on the recall level. Only a few examples of rationalization and no occurrences of reflectivity were found. From these results, the alignment between the verbal and visual aspects, in video reflections, do not appear to automatically lead to the ability to reflect more deeply. Cheng and Chau (2009) argued that additional training in how to reflect more deeply may be needed for students to make the step from recall to reflectivity.

Another approach to encouraging experiential and transformative learning through selfreflections has been tested in the form of team reflections. According to Veine et al. (2019, p. 153) "[b]y adding the different perspectives, students will be able to reveal assumptions, expand their understanding of their own actions and discover behaviors that are not visible to the individual" (cf. Brookfield, 2017). In the course design behind Veine et al. (2019), a team reflection contributed to $50 \%$ of the students' final grade. This assessment contributed to the 
constructive alignment within the course as "[r]eflection is framed both as a means (a learning activity they do) and an end (a skill that students develop for use throughout their lives” (p. 9). They concluded that such team reflections enable members to be able to "make better use of their productive potentials in the project work" by making processes visible through reflection (Veine et al., 2019). However, they emphasize that both students and staff need adequate support to construct and engage in such reflective processes.

White (2012) posits that in order to understand how students reflect, one must understand how they perceive reflection. Reflection has been shown to be a vital part of the learning process, and one's perception and value of something will affect if and how it is completed. To better understand students' perception of various methods of reflection (i.e. journaling and discussion), White interviewed students in focus groups. The students' qualitative statements showed they saw a clear connection between leadership and reflection, they preferred written reflections to discussions, and they were opposed to forced reflections, despite finding that making time for reflections on their own was difficult. The students' comments also showed a perceived connection between emotions and reflections, in that some mentioned that they "felt pressured" to make their responses more emotional than they really felt (2012, p. 150).

From this short overview of previous research on self-reflections in higher education, the importance can be seen of considering and clearly establishing how reflections are defined along with contextual factors, such as instructions, frequency, media, format and feedback. Self-reflections have been worked into course designs in various ways showing the advantages of various formats. White (2012) provides anecdotal evidence of students' preference for written reflections over discussions, while Cheng and Chau (2009) looked into the greater workload and motivation of video-based reflections. However, a greater understanding of students' perception of a wider range of formats and other contextual factors is still necessary to understand how students engage in such tasks.

This study aims to provide a better understanding of the effects of training, feedback and media formats on students' perception of the usefulness and depth of their reflections.

\section{Method}

This study was undertaken at the University of Applied Sciences and Arts Northwestern Switzerland (FHNW), School of Business, in the spring of 2020. Data was collected from a class of 27 undergraduate students in the final semester of their BSc International Management degree. These students were in the second semester of a 20-credit marketing specialization and the final semester of their BSc degree. A positive learning environment amongst students and between students and lecturers had already been established over the course of the autumn semester. For this reflection study, a questionnaire was developed and distributed before the spring semester, addressing key questions about students' learning style in general and their perception of the usefulness of self-reflections in particular.

In the questionnaire at the beginning of the semester, students were asked to indicate their perceptions of the usefulness of reflections to successfully complete the marketing specialization and for their desired career. They were also asked about their preferred media format for their reflection.

To earn the credits for this intense Marketing module, students had to submit a case study-based group assignment (30\% weight of grade) as well as several individual assignments (70\% weight of grade). The individual assignments consisted of an oral exam at the end of the semester plus four reflections, submitted during the semester in a variety of formats: two written papers, one vlog, and one written summary of a peer reflection. During the semester, lecturers supported students to improve their reflective practice by giving personal examples, by explaining the 
different depths of reflective expressions and by providing structured feedback on their submitted reflection. For the development of the more time-intense and technical vlog, lecturers provided clear instructions, recommendations for suitable software, self-reflection examples in form of vlogs of themselves and training via mentoring sessions. Students were therefore able to gain in-depth reflection experience (IDRE) during this module across a variety of media formats and therefore able to improve their reflective practice.

At the end of the semester, after the oral exams, students reported their changed perceptions in terms of the usefulness of reflection. This was done first in an online survey again, which was slightly adjusted from the first survey, to include new questions on (a) the benefit of the training and feedback provided and (b) the reason for their preference for a particular media format for self-reflection. After students completed the second survey, individual interviews with five students were organized. Individual students were selected to specifically provide a range of more in-depth perspectives. Students who had stated that self-reflections are not beneficial, even after the IDRE during the semester were invited. Survey respondents who indicated a preference for reflection using different media formats were also invited to be interviewed. The specific interest in the interviews was to understand students' reasons for their preference for a particular media format once the students had gained IDRE.

The students' responses to the two surveys were collected and compared to identify the key changes in students' perceptions. The data collected from the semi-structured interviews were transcribed and key quotes were selected to further substantiate the survey responses.

\section{Analysis}

Before the semester, most students noted in their answers that they had little reflection experience. The majority's preferred learning style was lectures, online tutorials and creating summaries. After having completed four reflections during the semester, students are not more inclined to designate self-reflections as their preferred learning style. Only a quarter of students indicated that self-reflection is one of their preferred learning styles, which did not change during the semester.

All students perceive lectures to be beneficial to passing a module. This also did not change during the semester. However, at the end of the semester significantly more students considered reflection to be beneficial for passing the module (up from $25 \%$ (6) to $44 \%$ (11) of students).

When interviewed about whether their perception of self-reflection changed over the year, the students' responses underscored their desire to be honest and improve.

"At the beginning, I was like ready to make a perfect self-reflection, you know like sugar-coat it and write it like how somebody else wants to like, you know like give someone the impression that everything is ok, but then during this I realized that for me I think I can learn a lot when I am just honest and just write it kinda like a journal or something... I just tried to be honest, you know what I mean? It changed a lot from last semester to this one.” (Interviewee 1)

"I think for me, when I wrote about my weaknesses, I really had to stand to them. And then I saw what I could improve, and I was like ok I really have to do this for next time. I didn't accomplish that as effectively as I wanted, but still I know where I have to work.” (Interviewee 2)

The survey responses regarding the link between lectures/ self-reflections and career benefits remained unchanged during the semester: three-quarters of students considered lectures most beneficial for their career and around half of the students considered reflections most beneficial for their career. At the beginning of the semester, reflections were considered by more students to be beneficial for their career than for passing a module (54\% (13) versus $25 \%$ (6) of students). 
After IDRE, self-reflections are considered by a similar number of students to be beneficial for their career and for passing a module (48\% (12) versus 44\% (11)).

When interviewed about the perceived benefits of self-reflections to their future careers and whether or not they would continue to complete reflections on their own, the students were almost unanimous. They generally expressed that they would not (regularly) complete such structured reflections unless required for their annual appraisals.

"It was really cool for the time being, but I can see myself saying yeah for sure it was a good experience, but then in the end maybe I would just forget to do it. It was kind of eye-opening for me to see my weaknesses and stuff, but for now I think I'm just going to do it in like in a year or two, maybe that would help me to see where I am, so that's maybe something I should think about." (Interviewee 1)

"Well I think I will be forced, because there is always that mid-term meeting with your boss. And then you always need to reflect and when you have some experience with reflection. Well, being here and reflecting on my work probably I will remember some things. 'Oh yeah I know how to structure my sentences. I know what a reflection looks like. Yeah and how to improve things. I think I will always need to do that in the future.” (Interviewee 2)

The number of students who expressed their impression of the uselessness of self-reflections to passing the module or for their career remained rather low over both surveys at around $15 \%$, showing that although self-reflection is generally not their most preferred learning style they see some value in it.

More than half the students consider self-reflections beneficial for learning from experience and personal development, however, there was a slight decrease, at the end of the semester, in the numbers of students who considered self-reflections beneficial for learning from experience.

At the beginning of the semester, 66\% (16) of students mentioned written papers as one of their preferred formats, which increased to 80\% (20) after IDRE. Vlogs increased as one of their formats from $17 \%$ (4) to $28 \%$ (7) and peer reflection decreased from $46 \%$ (11) to $32 \%$ (8).

A more detailed analysis of students' answers at the end of the semester shows that they have different preferences for their unique choice of format for self-reflections (one answer allowed): $56 \%$ (14) of students choose written paper, 24\% (6) vlog (despite the significant workload) and $20 \%$ (5) peer reflection.

Those interviewed highlighted the big workload that the vlog brought but also emphasized that they enjoyed the opportunity to be creative and express themselves in a different way.

"Because here you are required to consider a lot about yourself and your values. Further, you can be creative and really gain some new skills and knowledge in creating a video and editing it.” (Survey respondent A, open question response)

"I think everyone did a really great job and everyone put a lot of effort into it. I don't know, I think I worked on it for 10 hours, and I really liked it even if it was um a lot of effort that you had to put into it. But probably that's me, others are not so creative, they don't see why they should do that, but I liked that one the most.” (Interviewee 1)

"I think in the video, for me, I think I can express myself easier because there are so many things you can edit and so many ways where you can like bring in your creativity and show what kind of person you are. I think that fits better in a video." (Interviewee 2)

"I preferred the video, because I could get really creative. I mean at the beginning I was not sure if I hit the spot with it, so um so I was a bit unsure, but in the end, I also had this sense of 
accomplishment when I looked at it. And this was really, really cool... I was like, 'hey look I did that', so in addition to being like honest about myself and stuff like in my self-reflections, I also had this kind of achievement to just like make something creative, that was really cool." (Interviewee 3)

Students who chose the written paper as their preferred format appreciated the focus they were able to have and the extra time as no additional tool was required.

"It's slow and you therefore have a lot of time to think about yourself, your performance and your behaviour while you write it.” (Survey respondent B)

"You have more time to reflect and also search for the appropriate words. I can simply better express myself in writing. Further, it is less time-consuming than creating a video reflection, but has the same effect.” (Survey respondent C)

"You can take more time to go through the passed lectures and think about it. Furthermore, you have the time to look for more information in order to be able to write your thoughts properly." (Survey respondent D)

Students who chose the peer reflection as their preferred format appreciated the opportunity for discussion and feedback from other students.

"I liked exchanging what comes into my mind with someone else. Also, thanks to a discussion you might get direct feedback or see how others perceived the same situation. That is extremely helpful. Still, writing allows you to think deeper about your topic compared to a talk. So I enjoyed talking about what I've written.” (Survey respondent E)

"You have to evaluate yourself but moreover, you also get inputs from other students, which are essential for personal development, because how you perceive yourself deviates from how others see and perceive you. And when it comes to an assignment, it is always good to have more than one set of eyes to look at a topic.” (Survey respondent F)

As expected, no student mentioned that the intense training and feedback provided was unimportant for their reflective practice, with $40 \%$ (10) of students rating it as neutral and $60 \%$ (15) as important. Students provided meaningful insights of what helped them most to improve their reflective practice, with answers ranging from personal feedback, mentoring sessions, examples and explanations of reflective verbs to having time for training and experiencing selfreflections.

"At the start I really didn't know what to write. And then I just was like 'ok just be honest and see where it goes'. And then I got really positive feedback, so I knew this was the way to go. And so I just continued, and from this point on, I really liked the self-reflections actually, because then I always knew what I could write about.” (Interviewee 3).

Although a platform for students to show-off their vlogs and receive peer feedback as in Cheng and Chau (2009) was not implemented in this study, comments in the survey and interviews indicated that students shared their vlogs with each other. In commenting on this, one student indirectly addressed the aspect of audience and purpose.

"Well I think I was able to express my personality [in the vlog], to like show who I am and what I value. Whereas in written reflections you just don't know where you should put that in. It's always important to see the person behind it and so it was really nice to show where my values lie and everything. I even thought about putting it on LinkedIn. I didn't do it, but all the people who saw it were like, "oh it's so nice". Then the questioned why I did it for whom or for what.” (Interviewee 1) 
Students were generally very interested, appreciative, and supportive of this study. Students showed a high degree of motivation in their reflections due to the positive learning environment amongst the students and lecturers, which is in line with the studies from Bruno \& Dell'Aversana (2018) and the feedback they received.

"Thank you all a lot for all the support ... I really enjoyed the classes and I am definitely happy I choose Marketing as my Specialization field and looking forward to starting my career as a Marketing Manager.” (Survey respondent A)

\section{Discussion}

It was interesting for us to observe that business students in the 21st century still rate lectures as their preferred learning style, considering the importance of self-reflection for leadership development and future careers for our students. It is, however, encouraging that a quarter of students mentioned self-reflection as one of their preferred learning styles and that half of the students consider self-reflection beneficial for their future career. These answers remained unchanged over the semester. Moreover, only $15 \%$ of students found self-reflections useless, which remained again unchanged.

As noted by Cheng and Chau (2009), students in this study stated that reflection training and feedback is hugely beneficial for improving their reflective practice. From their detailed answers, one can conclude that students appreciated the wide range of feedback and training opportunities that were offered.

A number of students changed their preferences in terms of preferred media format for reflection during the semester. Our findings confirm that students were able to develop stronger preferences due to an in-depth reflection experience (IDRE) and exposure to different reflection formats. One can also now better understand the reasons why students prefer a particular media format:

- New skills/ experience learnt (vlog)

- Allows creativity (vlog)

- Personal (talking) preference (vlog)

- Allows deeper reflection (vlog \& written paper)

- Focus on reflection not medium (written paper)

- Opportunity for feedback (written paper)

- Workload/ time considerations (written paper and peer reflection, versus vlog)

- Direct feedback and other perspectives and discussion (peer reflection)

- Dependency on others (against peer reflection)

Another interesting change observed was that at the end of the semester more students rated reflection as beneficial for passing a module. This change in students' perception may relate to students' awareness of the relatively easy possibility to gain points for their grade by submitting the four reflections.

\section{Conclusion}

This study aimed to build on previous research on the use of self-reflections in experiential learning to better understand three aspects related to the use of self-reflections in an undergraduate business studies degree program. 
- The student's change in perception of the role of reflection in their learning, both for their degrees and for their development as future leaders.

- The effects of training, feedback and media formats on students' perception of the usefulness of their reflections.

- Ways in which lecturers can best use various media formats, feedback and training to support and encourage students' development.

In this study, the survey results showed few changes in student's perceived module-completion or career benefits. However, when interviewed, the students indicated an increased ability to reflect honestly and a greater desire to confront their weaknesses. Concerning the media format of the reflection, the students developed stronger opinions throughout the semester. There was an increased preference for written and video-based reflections and a drop in preference for peer-based reflections. In the survey's open-questions and the interviews, students' responses expressed personal reasons for their preferred media formats, indicating that different students may be able to better express themselves in different formats. This has potential consequences for how lecturers integrate self-reflections into our curriculum. Including a variety of reflection types may speak to a diverse student body and provide valuable practice in various reflective practices, ultimately giving students a wider range of reflective tools.

The interview responses also support Chang and Chau's (2009) claim that peer-feedback is a motivator. Although our students were not required to share their vlogs with each other, the interviewees positively commented on the compliments that they received and that this was rewarding. Thus, both lecturers and further research should consider how peer-feedback, as well as a clearly a defined audience and purpose, should be included in the curriculum design. This would better enable us to understand the effects these factors have on the students' motivation and their reflections. Future research is also needed on the effect of the media format on the depth of reflection. This study has shown that experience using different reflection formats affects which format students prefer and that workload is not the predominant factor. However, gaining a better understanding of how a greater variety of media formats affect student motivation and reflection depth (cf. Bruno \& Dell'Aversana, 2018; Cheng \& Chau, 2009 for levels of depth) would be beneficial to future implementation.

A weakness that this paper suffered from was also the small number of participants. Future research that could quantify the effect of various factors on motivation and depth is necessary to substantiate these claims and also provide a more focused direction for future research.

\section{References}

Boud, D. (2001). Using Journal Writing to Enhance Reflective Practice. New Directions for Adult and Continuing Education, 90, 9-18.

Brookfield, S. (2017). Becoming a Critically Reflective Teacher (2nd ed.). San Francisco: Jossey-Bass.

Bruno, A., \& Dell'Aversana, G. (2018). Reflective practicum in higher education: the influence of the learning environment on the quality of learning. Assessment \& Evaluation in Higher Education, 43(3), 345-358. https://doi.org/10.1080/02602938.2017.1344823

Cheng, G., \& Chau, J. (2009). Digital video for fostering self-reflection in an ePortfolio environment. Learning, Media and Technology, 34(4), 337-350. https://doi.org/10.1080/ 17439880903338614

Dyment, J. E., \& Connell, T. S. O. (2011). Assessing the quality of reflection in student journals: a review of the research. Teaching in Higher Education, 16(1), 81-97. 
https://doi.org/10.1080/13562517.2010.507308

Kets de Vries, M. F. R., \& Korotov, K. (2012). Transformational Leadership Development Programs. In S. Snook, N. Nohria, \& R. Khurana (Eds.), The Handbook for Teaching Leadership: Knowing, Doing, and Being (pp. 263-281). Los Angeles, London, New Delhi, Singapore, Washington D.c.: Sage.

Kolb, D.A. (1984). Experiential learning: Experience as the source of learning and development. Englewood Cliffs, NJ: Prentice-Hall

Kreber, C. (2004). An analysis of two models of reflection and their implications for educational development An Analysis of Two Models of Reflection and their Implications for Educational Development. International Journal for Academic Development, 9(1), 2949. https://doi.org/10.1080/1360144042000296044

Leal-rodríguez, A. L., \& Albort-morant, G. (2019). Promoting innovative experiential learning practices to improve academic performance: Empirical evidence from a Spanish Business School. Journal of Innovation and Knowledge, 4(2), 97-103. https://doi.org/10.1016/j.jik .2017.12.001

Mezirow, J. (1991). Transformative dimensions of adult learning. San Francisco: Jossey-Bass.

Moreno, R., \& Mayer, R. E. (2000). A Learner-Centered Approach to Multimedia Explanations: Deriving Instructional Design Principles from Cognitive Theory. Interactive Multimedia Electronic Journal of Computer-Enhanced Learning, 2(2). Retrieved from http://imej.wfu.edu/articles/2000/2/05/index.asp

Orland-barak, L. (2007). Portfolios as evidence of reflective practice: what remains 'untold.' Educational Research, 47(1), 25-44. https://doi.org/10.1080/0013188042000337541

Schön, D. (1983). The reflective practitioner: how professionals think in action. New York: Basic Books

Sweller, J., Merrienboer, J. J. G. Van, \& Paas, F. G. W. C. (1998). Cognitive Architecture and Instructional Design. 10(3), 251-296.

Threlfall, S. J. (2014). E-journals: towards critical and independent reflective practice for students in higher education. Reflective Practice, 15(3), 317-332. https://doi.org/10.1080/ 14623943.2014.900012

Tosh, D., Light, T. P., Fleming, K., \& Haywood, J. (2005). Engagement with Electronic Portfolios: Challenges from the Student Perspective. Canadian Journal of Learning and Technology, 31(3).

Veine, S., Anderson, M. K., Andersen, N. H., Espenes, C., Søyland, T. B., Wallin, P., \& Reams, J. (2019). Reflection as a core student learning activity in higher education - Insights from nearly two decades of academic development. International Journal for Academic Development, 25(2), 147-161. https://doi.org/10.1080/1360144X.2019.1659797

White, J. V. (2012). Students' Perception of the Role of Reflection in Leadership Learning. Journal of Leadership Education, 11(2), 140-157.

Zimmerman, B., \& Schunk, D. H. (1989). Sellf-Regulated Learning and Academic Achievement: Theory, Research, and Practice. New York: Springer-Verlag. 